\title{
Neurological findings and outcome in adult cerebral malaria
}

\author{
M.A. Sattar, Hasnat Waheedul Hoque, M. Robed Amin, M.A. Faiz and M. Ridwanur Rahman \\ Department of Medicine, Chittagong Medical College, Chittagong, Bangladesh. \\ e-mail:dr.sattar_cox@yahoo.com
}

\begin{abstract}
The neurological findings of 100 patients of adult cerebral malaria were studied. The commonest neurological feature was symmetrical upper motor neuron lesion as evidenced by exaggerated tendon reflexes and bilateral planter extensor (61\%). Twenty two percent had features of meningeal irritation and/or meningism. Abnormal posturing occurred decerebrate rigidity (6\%) and decorticate rigidity (4\%) with or without opisthotonus, focal neurological deficit was noted in 5\% cases. Pupillary size and reaction were normal in $86 \%$, poor in $14 \%$. Corneal reflexes were absent in $4 \%$ cases. Fundoscopy showed retinal hemorrhage in $16 \%$, papilloedema is $3 \%$ and exudates in $1 \%$. Majority of the patients recovered (80\%) without any persistent neurological sequelae at the time of discharge from hospital and death rate was $20 \%$. Patients having focal neurological deficit, disconjugate gaze, poor pupillary reaction, absent corneal reflex and papilloedema were more susceptible to death. Delay in hospitalization and deep coma were also associated with increased mortality, whereas early hospitalization and proper nursing care could reduce mortality.
\end{abstract}

\section{Introduction}

Malaria is the most important parasitic disease in man. It is estimated that 110 million clinical cases of malaria and between one and two million deaths associate with Plasmodium falciparum occur each year worldwide ${ }^{1}$. Cerebral malaria is the most important complication of falciparum malaria and also the leading cause of death in malaria ${ }^{2,3}$. Cerebral malaria is defined as an acute, symmetric encephalopathy associated with sequestration of parasites erythrocytes in the cerebral vessels and capillaries in patients with falciparum malaria ${ }^{4}$. The World Health Organization has laid down definite guideline for diagnosis and management of cerebral malaria $^{5}$. This definition requires the presence of unrousable coma using the Glasgow Coma Scale (GCS), exclusion of other encephalitides, especially bacterial meningitis and if possible, locally prevalent encephalitis and the finding of asexual forms of $P$. falciparum in the blood film.

The study was conducted to see the neurological findings and outcome in adult cerebral malaria cases and to compare those findings between the death and survivors.

\section{Materials and Methods}

This study was carried out from August 2000 to September 2001. One hundred cases (75 males and
25 females) of cerebral malaria suffering from unrousable coma $(\mathrm{GCS}<9)$ with fever or history of fever over last 48 hours with positive blood slide for asexual stage of $P$. falciparum, were included in this study. Assessment of patients based on clinical history, physical, including neurological examinations using GCS. Blood films were taken for thick and thin film for malarial parasites and random blood sugar was analyzed. Data was recorded on a predesigned proforma and analyzed with appropriate statistical formula.

\section{Result}

Age ranges of the patients were from 18 to 60 years. Majority of the patients were below 50 years. Only 8 were above 50 years of age, of which 5 $(62.5 \%)$ had died. In this study mean ( \pm SD) duration of illness before hospitalization was $7.1 \pm$ 2.3 days among the survivors and $5.9 \pm 1.9$ days in fatal cases. Mean duration of severe illness before hospitalization was $1.4 \pm 1.0$ days among the survivors and $1.6 \pm 1.0$ days among the dead.

Convulsion was also encountered in 22\% patient before admission and 18\% patients after admission. Death rate was high in patient related with associated with renal failure (57.9\%) and with deep breathing (52.4\%). Patients who recovered fully, had mean $( \pm \mathrm{SD})$ GCS was $7.8 \pm 1.01$ on admission compared to $6.90 \pm 1.48$ in patients who had died. 
The commonest neurological finding noted was exaggerated deep tendon reflexes and bilateral extensor plantar reflexes (61\%). Other features observed were signs of meningeal irritation/ meningism in 22 patients, decerebrate posture in 6 , decorticate posture in 4 patients. Focal neurological deficit (asymmetric deep tendon reflex, planter response, mono-paresis, asymmetric pupil) in 5 cases. Four patients out of those five had died (Table I).

Sixty two patients had normal eye movement and 32 had sustained upward gaze. Disconjugate gaze was noted in 4 cases out of which 3 died. Corneal reflex was lost/absent in 4 patients, out of which 3 died. Pupillary size was normal in 88 and small in 12 patients. Out of normal 78 recovered and 10 died. Out of 12 patients with small pupil, 10 died.

Table I: Pattern of neurological manifestations

\begin{tabular}{lrrr}
\hline Variables & Total & \multicolumn{3}{c}{ Outcome } \\
\cline { 3 - 4 } & & Full recovery & Death \\
\hline Sign of meningeal & 22 & 19 & 3 \\
irritation/ meningism & & & \\
Cranial nerve (III, VI) & 97 & 78 & 19 \\
$\quad$ Intact & 3 & 2 & 1 \\
$\quad$ Lost & & & \\
Deep tendon reflex (Rt.\& Lt.) & 87 & 72 & 15 \\
$\quad$ Present & 6 & 5 & 1 \\
$\quad$ Brisk & 7 & 3 & 4 \\
$\quad$ Absent & 4 & 4 & - \\
$\quad$ Decorticate posture & 6 & 5 & 1 \\
$\quad$ Decerebrate posture & & & \\
Planter response & 31 & 26 & 5 \\
$\quad$ Flexor & 61 & 49 & 12 \\
Extensor & 8 & 5 & 3 \\
Equivocal & 5 & 1 & 4 \\
Focal neurological deficit & & & \\
\hline
\end{tabular}

Table II: Pattern of ophthalmic manifestations (on admission)

\begin{tabular}{lrrr}
\hline Variables & Total & \multicolumn{2}{c}{ Outcome } \\
\cline { 3 - 4 } & & \multicolumn{2}{c}{ Full } \\
recovery & Death \\
& & & \\
\hline Eye movement & 62 & 51 & 11 \\
$\quad$ Normal & 2 & 2 & 0 \\
$\quad$ Doll's eye movement negative & 32 & 26 & 6 \\
$\quad$ Sustained upward gaze & 4 & 1 & 3 \\
$\quad$ Disconjugate gaze & & & \\
Corneal reflex & 96 & 79 & 17 \\
$\quad$ Present & 4 & 1 & 3 \\
$\quad$ Lost & & & \\
Pupil size & 88 & 78 & 10 \\
$\quad$ Normal & 12 & 2 & 10 \\
$\quad$ Small & & & \\
Pupillary reaction & 86 & 74 & 12 \\
$\quad$ Normal & 14 & 6 & 8 \\
$\quad$ Poor & 99 & 79 & 20 \\
$\quad$ Pupillary symmetry & & & \\
Fundoscopy & 80 & 68 & 12 \\
$\quad$ Normal & 1 & 1 & -- \\
$\quad$ Exudate & 3 & 13 & 3 \\
$\quad$ Hemorrhage & & -- & 3 \\
$\quad$ Papilloedema & &
\end{tabular}

In this study, 80 patients had normal fundus. There was retinal hemorrhage in 16 patients, papilloedema in 3 and exudate in 1 . Out of them, all 3 patients with papilloedema had died, followed by 3 with hemorrhage, 12 with normal fundoscopy. There was no death in patients with exudate (Table II).

Eighty patients of adult cerebral malaria recovered without any neurological sequele and 20 had died.

\section{Discussion}

Majority of the cerebral malaria cases occurred in males in their active period of life incurring great financial loss to their families and hence to the nations. Elderly patient were more susceptible to death demanding special care. This findings are similar with other study from the same hospital ${ }^{6,7}$. Duration of severe illness was longer at hospitalization in deaths than in survivors signifying the need of early hospitalization in cerebral malaria.

Patient with low GCS during hospitalization were associated with poor outcome in this study. Similar report was also documented in a study by Faiz et $\mathrm{al}^{6}$.

The commonest neurological feature was symmetrical upper motor neuron lesion as evidenced by bilateral planter extensor and exaggerated tendon reflexes. This sign might be very helpful in diagnosing cerebral malaria in endemic zone. Patient with cerebral malaria had features of meningeal irritation and/or meningism but neck rigidity, kerning's sign and photophobia was absent which helped to exclude meningitis.

Sustained upward gaze was characteristically found in cerebral malaria. Disconjogate gaze and loss/absent corneal reflex, were associated with increased mortality. Pupillary size was important prognostic guide as more than three fourths of the patients with small pupil and poor reaction to light had died. However, death rate was high in patient related with associated renal failure and with deep breathing. These findings are consistent with findings of Chowdhury et $\mathrm{al}^{7}$.

Ocular fundi revealed normal in majority of patients and hemorrhage, papilloedema, exudates in others. Retinal hemorrhage was not correlated with mortality but papilloedema was associated with increased mortality. Lewallen et al (1996) found the relative risk of death in patients with papilloedema was 6.7 times that in patients without papilloedemia ${ }^{8}$. Neurological sequelae like monoplegia, neuropsychiatric manifestation, cranial nerve lesions and extrapyramidal tremor were 
absent in this study in comparison with African studies which is different with us as they included childhood cerebral malaria ${ }^{11,12}$, but similar to cerebral malaria in Thai adult. Among the Thai adults, more than 95 percent survivors of malaria lacked even transient neurological sequelae ${ }^{13}$ which is consistent with the findings in present study.

In conclusion, majority of the patients with cerebral malaria recovered without persistent neurological sequele at the time of discharge from hospital but patients having focal neurological deficit, disconjugate gaze, poor pupillary reaction, absent corneal reflex and papilloedema were more susceptible to death, where early hospitalization and proper nursing care could reduce mortality.

\section{Reference}

1. WHO practical chemotherapy of malaria. Technical report 805. Geneva, World Health organization, 1990, p 7.

2. Bangali AM. Border malaria: Bangladesh. J Chittagong Med Coll Teachers Assoc. 1996; 7: 95-97.

3. Faiz MA. A study of clinical presentation of malaria. Bangladesh Med J. 1982; 11: 41-52.

4. Macpherson GG, Warrell MJ, While NJ, Looareesuwa S, Warrell DA. Human cerebral malaria: A quantitative ultrastructural analysis of parasitized erythrocyte sequestration. Am J Path. 1985; 119: 385-410.

5. Warrell DA, Molyneux ME, Beales PF. Severe and complicated malaria. Tran R Soc Trop Med Hyg. 1990; 84(Suppl 2): 1-65.

6. Faiz MA, Rahman MR, Hossain MA, Rashid HA. Cerebral malaria: A study of 104 cases. Bangladesh Med Res Counc Bull. 1998; 24: 35-42.

7. Chowdhury D, Yunus EB, Dutta PK. Acute renal failure in malaria. J Chittagong Med Coll Teachers Assoc. 1996; 7: 69-74.

8. Lewallen S, Bakker $\mathrm{H}$, Taylor TE, Wills BA, Courtright P, Molyneux ME. Retinal findings predictive of outcome in cerebral malaria. Trans Royal Soc Trop Med Hyg. 1996; 90: 144-46.

9. Brewster DR, Kwiatkowski D, White NJ. Neurological sequele of cerebral malaria in children. Lancet 1990; 336: 1039-43.

10. Molyneux ME, Taylor TE, Wirima JJ, Borhstein A. Clinical features and prognostic indicators in pediatric cerebral malaria: A study of 131 comatose Malawian children. Qrt J Med. 1989; 71: 441-59.

11. Warrel DA. The impact of clinical investigation on the two third world diseases: Cerebral malaria and louse borne relapsing fever. In: Advanced medicine. Saunders KB (ed). $19^{\text {th }}$ ed. London, Pitman Medical, 1983, pp 99-111. 